\title{
Herstelgerichte sancties en het strafbegrip
}

\author{
John Blads rechtstheoretische visie
}

Bas van Stokkom

Aan het allereerste nummer van dit tijdschrift (2001, nr. 1) leverde John Blad maar liefst drie bijdragen: een toelichting op de vraag waarom een tijdschrift voor herstelrecht nodig is, een toelichting op de oprichting van het Forum voor Herstelrecht (een voorloper van Restorative Justice Nederland) en een rechtstheoretisch artikel getiteld 'Van strafrecht naar herstelrecht?'. In dit essay zal ik me focussen op de opvattingen van Blad over het sanctiebegrip van het herstelrecht en het strafbegrip van het strafrecht. Wat is de status van een herstelsanctie? Waarin wijkt die sanctie af van een opgelegde strafrechtelijke sanctie? Als geen ander heeft John Blad op deze thematiek gereflecteerd.

In 'Het Tijdschrift voor Herstelrecht: waarom en waartoe?' wijst Blad erop dat het erom gaat 'het rechtssysteem in verschillende opzichten meer rechtvaardig te maken, met name ten opzichte van slachtoffers. Dit impliceert dat de morele plicht om schade te herstellen centraal komt te staan' (2001a: 1). Maar het gaat ook om het bevorderen van een cultuur waarin conflicten vreedzaam kunnen worden uitgesproken tussen de betrokkenen. Blad plaatst dat tegenover het aloude culturele model van het strafrecht 'dat ons voorhoudt dat op beschadigend gedrag straf moet volgen' (2001a: 2). De belangrijkste tekorten van dat model zijn ten eerste dat de dader niet van de fouten leert die hij heeft gemaakt en ten tweede dat het slachtoffer met onbeantwoorde vragen en schade blijft zitten. Hij verwijst in dit verband naar de strafsocioloog David Garland:

'Als samenleving lijken we niet zonder strafrecht te kunnen, maar de toepassing van (demonstratief stigmatiserend) strafrecht is in elk individueel geval eigenlijk een kleine tragedie met overwegend schadelijke sociale consequenties' (2001a: 2).

We zouden daarom zeer terughoudend moeten zijn met het gebruik van beoogde leedtoevoeging. De leedstraf zou een laatste toevlucht moeten zijn: vanwege de beschadiging die deze straf bewerkstelligt, is er een publiek belang om strafoplegging zo veel mogelijk te vermijden en uitstoting van de dader als 'crimineel' te voorkomen.

Daarnaast wijst Blad op een belangrijk verschil: terwijl het strafrecht focust op 'de juridische betekenissen van gedragingen en hun rechtsgevolgen', beoogt het herstelrecht toegang te verkrijgen 'tot de gebeurtenissen en hun gevolgen in morele en (psycho-)sociale zin' (2001a: 3). Het draait dus om de sociale en morele betekenis van delicten en om het herstellen wat herstelbaar is, niet om het strafbare feit. 
In 'Van strafrecht naar herstelrecht?' borduurt Blad daarop voort. Het formele recht hecht alleen aan juridische constructies. Zo worden in het strafrecht de strafbepalingen vanouds gerelateerd aan een specifieke categorie van handelingen die indruisen tegen de bestaansvoorwaarden van het collectief. Straf geldt daarbij als opzettelijke leedtoevoeging vanwege de overheid voor het begane delict. In de vroege dagen van het strafrecht moest de 'bedreigde, gefixeerde straf' van het wetboek een voorspelbaar nadelig saldo opleveren.

Toch hebben zich interessante ontwikkelingen voorgedaan die tot een minder orthodox en star strafrecht hebben geleid. Daarbij wijst Blad onder andere op de Moderne Richting en zijn nadruk op speciale preventie. Sindsdien heeft zich een proces van sanctiedifferentiatie voltrokken die de straftoemetingsruimte veel groter heeft gemaakt. Interessant daarbij is het beleidssepot, de beslissing om niet te vervolgen. Tegelijk is een proces van sanctieproliferatie ontstaan, de verspreiding van sanctiebevoegdheden naar andere organen dan de strafrechter, waaronder het Openbaar Ministerie. In dit veld van sanctiedifferentiatie en -proliferatie kunnen volgens Blad ook alternatieve, herstelgerichte sanctiepraktijken tot wasdom komen, waaronder Halt-projecten en dienstverlening ('arbeid ten algemenen nutte'). Dat roept vragen op: wordt door middel van deze alternatieven 'in feite de leedstraf op nieuwe manieren ... uitgedeeld, nu met toevoeging van herstelverplichtingen' of kan 'herstel de leedstraf op den duur ... terugdringen naar zijn positie van ultimum remedium?' (2001b: 48).

Bezien tegen deze achtergronden benadrukt Blad vervolgens dat het Tijdschrift voor Herstelrecht een rechtstheorie van het herstelrecht wil bevorderen. Daartoe legt hij enkele 'nog lang niet voldoende uitgewerkte gedachten' voor. Ten eerste is het reëel om - met criminoloog Willem de Haan - misdaad en straf niet te zien als actie en reactie, maar als 'spiralling cycles of harm'. Misdaad en straf zouden vervangen kunnen worden door de enkelvoudige claim van 'redress' ('herstel' of 'verhaal'), dat aansluit op de notie van 'inclusief straffen' (2001b: 49). Wellicht kan het strafbegrip beter gefocust worden op 'tot de orde roepen' en 'terechtwijzen' (2001b: 50). Dit terechtwijzen zou idealiter gecombineerd kunnen worden met het faciliteren van een leerproces bij de dader, waarbij confrontatie met de aangerichte schade en de persoon van de benadeelde kunnen bijdragen aan 'een groter inzicht in de verwerpelijke gevolgen van zijn handelen' (2001b: 50). Dat veronderstelt 'een eerder moreel dan juridisch gesprek over het delict', waarbij ook eerdere normschendingen tegenover de dader betrokken kunnen worden. Dat brengt actief zelfonderzoek en onderzoek van sociale verhoudingen met zich.

Op deze manier kunnen we afscheid nemen van het gesloten mensbeeld dat kenmerkend was voor zowel het klassieke strafrecht (de 'rationele, calculerende dader') als de moderne richting (de 'gedetermineerde dader'). In die lange tijd dominante perspectieven meende men wel te weten hoe de mens in elkaar zit en hoe hij functioneert. Om die reden bestond 'niet bijzonder veel interesse voor het verhaal van de verdachte' (2001b: 51). Dat laatste begrip sluit aan bij de labelingbenadering die erop wijst dat de identiteit van de dader niet vastligt, maar in relatie tot anderen ontstaat. Het gaat om een open mensbeeld, 'onbepaald en interactief bepaalbaar', een theoretische positie die zich verzet tegen stigmatisering en stereotypering van personen, omdat die een onderdrukkende werking hebben 
(2001b: 51). In termen van rechtsgeleerde Jack ter Heide gaat het om een 'kenbaar maken van de biografische situatie', een verhaal dat zich ontwikkelt in de richting van een feilbare en kwetsbare medemens, dat een basis schept voor bewuste zelfverandering.

Blad merkt ten slotte op dat deze rechtstheorie wel erg veel aandacht geeft aan 'de dader', hetgeen ongebruikelijk is voor een herstelrechtelijk benadering. Dat zij hem 'vergeven', want het ging hem er in dit stuk vooral om een constructieve draai aan straf te geven.

$\mathrm{Al}$ eerder, in het artikel 'Strafrecht en bemiddeling: opkomst en toekomst van herstelrecht in Nederland' (2000) had Blad soortgelijke gedachten ontwikkeld. In die tekst omschreef hij de leedstraf als 'degraderend en desintegrerend' en onverenigbaar met 'het rehabiliterende en integrerende herstel' (2000: 69). Het opleggen van een leedstraf betekent 'voor alle betrokkenen in de meeste gevallen alleen maar een nog groter verlies' (2000: 69).

Blad keert zich in dat verband ook tegen de verenigingstheorie die

'feitelijke onverenigbaarheden als verenigd voorstelt: hoe zou demonstratieve vergelding zich laten verenigen met het resocialisatie streven? (terwijl de generaal-preventieve kracht ervan dubieus is) ... De verenigingstheorie legitimeert eigenlijk alle denkbare legale interventies maar zegt ons niets over de vraag hoe in een bepaald geval zou moeten worden gereageerd. Sterker nog, hij roept de gedachte op dat als de sanctie niet "goed" is in speciaal preventieve zin, hij dat wel zal zijn vanuit vergeldingsoogpunt en andersom. Wat maakt het uit? Belangrijk is dat we straffen!' (2000: 62).

Tegen deze achtergrond pleit hij voor een duidelijke prioriteit van de herstelsanctie. De herstelovereenkomst die voortvloeit uit de bemiddeling waarin wordt vastgelegd hoe de dader de schade zal herstellen en de benadeelde uitdrukt dat hij deze herstelhandelingen aanvaardt, acht hij in feite een publiekrechtelijke overeenkomst. Immers, de strafrechter of officier van justitie aanvaardt die overeenkomst als zijnde in het algemeen belang, voor zover de overeenkomst ook een herstellende verplichting naar de samenleving toe impliceert.

Overigens, de mogelijkheid van het opleggen van een leedstraf moet volgens Blad wel blijven bestaan, omdat er situaties zijn waarin

'een uitdrukkelijke, expressieve bestraffing onontkoombaar is (...) Gedacht moet dan worden aan uiterst schokkende inbreuken op de fysieke integriteit, waarna een publieke vergeldings- of beveiligingsbehoefte krachtig gevoeld wordt' (2000: 69).

In zulke gevallen 'kan de strafprocedure zelf een herstellende kracht hebben', hoewel ook dan de schadelijke gevolgen van het delict verminderd dienen te worden en de criminalisering van de dader 'actief wordt vermeden' (2000: 69).

Het concept van opzettelijke leedtoevoeging heeft volgens Blad overigens alleen nog relevantie voor zover het gaat om de onvoorwaardelijke strafoplegging door 
de strafrechter (2000: 62). Straffen die in het teken staan van trainen en leren kunnen alleen maar op verwrongen wijze een vorm van leedtoevoeging worden genoemd. De voorwaardelijke vrijheidsstraf moet in weerwil van de bewoording worden gezien als een geheel anders gemotiveerde, zelfstandige sanctie 'met een waarde vanuit het opvoedkundige denken van de moderne richting' (2000: 62).

De vraag in hoeverre bij een herstelrechtelijke afdoening nu sprake is van bestraffing, heeft John Blad vooral opgepakt in een studie getiteld 'Het sanctieconcept van het herstelrecht' (2011). Gaat het hier om een alternatief voor bestraffing zoals Lode Walgrave (2008) bepleit of om een alternatieve straf zoals uiteengezet door rechtsfilosoof Antony Duff (1992). Walgrave vereenzelvigt straf met de leedstraf, hetgeen voor hem reden is het strafbegrip ter discussie te stellen. Walgrave heeft het vooral gemunt op het a priori dat op elke misdaad een straf moet volgen en ziet de leedstraf als een ethisch negatieve activiteit die niet bijdraagt aan het herstel van aangedaan leed en schade van het slachtoffer en de samenleving. Verder redeneert Walgrave dat bij herstelsancties intentionele leedtoevoeging ontbreekt, ook al worden die sancties opgelegd en zullen die meestal pijnlijk en belastend zijn voor de dader.

Walgraves visie is - zoals bekend - bekritiseerd door Duff die meent dat herstelrecht juist alleen door vergelding - het redresseren van onrecht - herstellend kan zijn. Duff pleit voor een proces van morele communicatie, waarin de berouwvolle dader zich het onrecht 'toe-eigent' ('ja, ik ben verantwoordelijk') en afstand neemt van de wandaad. Dat betekent dat de herstelprocedure in strafzaken een vorm van lijden moet instigeren en tevens een publieke veroordeling van het onrecht moet inhouden.

John Blad heeft zijn eigen positie in dit debat als volgt verwoord. Hij kritiseert Duff, omdat hij het beeld schetst van mediation als een traditionele strafprocedure waarin sancties worden bepaald. Dat brengt een element van onvrijwilligheid met zich dat afbreuk doet aan vrijwillig aanvaarde herstelverplichtingen. Tegelijkertijd is in mediation in strafzaken van een 'soevereine oplegging' geen sprake. De justitiële autoriteiten doen een 'herstelrechtelijk aanbod' en stellen daarmee het opleggen van een maatregel of straf uit. Maar Blad heeft ook een bedenking bij Walgraves visie: de reparatoire sanctie die wordt opgelegd kan moeilijk anders gezien worden dan als straf. Hij concludeert dat het sanctieconcept van het herstelrecht in beginsel reparatoir is, maar dat dit reparatieve eerder normatief en moreel van aard is dan financieel. Het gaat om actief toe-eigenen van verantwoordelijkheid en op basis daarvan genoegdoening aan het slachtoffer bieden. Die 'morele reparatie' kan vergeldend worden genoemd, maar staat ver af van een vergeldingsopvatting die door afschrikking en disproportionele bestraffing 'vervuild' is geraakt. Anderzijds is morele reparatie goed verenigbaar met positieve generale preventie (de normbevestiging), speciale preventie en conflictoplossing.

Blads gedachtegang in 'Het sanctieconcept van het herstelrecht' is in een aantal opzichten leidraad geworden voor het Voorstel van Wet strekkende tot de invoering van een herstelgerichte afdoening via bemiddeling in strafzaken in het Wetboek van 
Strafvordering, inclusief Memorie van Toelichting, dat hij samen met Jacques Claessen, Gert Jan Slump, Anneke van Hoek, Annemieke Wolthuis en Theo de Roos schreef. De herstelrechtelijke sanctie refereert aan een herstelgerichte wijze van sanctioneren, waarbij het slachtoffer en de verdachte actief betrokken zijn (Claessen et al., 2017: 31). De kern daarvan is het aangaan van een herstelverplichting. Tegelijk is de herstelgerichte afdoening 'een "tot de normatieve orde roepende" interventievorm die de (bekennende) dader in staat stelt om zich te distantiëren van zijn strafbare handelen' (Claessen et al., 2017: 21). Deze vorm van afdoening 'dient prioritair te worden onderzocht', dat wil zeggen dat de focus primair op mogelijke (vrijwillig geaccepteerde) herstelverplichtingen wordt gelegd, en dan pas op strafrechtelijke sancties. Daarnaast verbindt het OM ten minste een voorwaardelijk sepot aan de vaststellingsovereenkomst, 'met als bijzondere voorwaarde dat de overeenkomst volledig wordt nageleefd' (Claessen et al., 2017: 13). Deze sanctie wordt, indien noodzakelijk, aangevuld met 'formele sancties' die overigens 'zo herstelgericht mogelijk worden gekozen, dat wil concreet zeggen dat aan een positief bemiddelingsresultaat in beginsel alleen herstelgerichte en/of vrijheidsbeperkende strafrechtelijke sancties worden verbonden (denk hierbij aan een taakstraf)' (Claessen et al., 2017: 32).

In een interview met Renée Kool en Annemieke Wolthuis (2019) herhaalt John Blad dat 'we de ambitie moeten hebben om van het herstelrecht een gevestigd positief recht te maken' (2019: 61). Het zelfbeeld van het klassieke strafrecht, vooral het gesloten mensbeeld dat eruit naar voren komt, klopt niet meer. De dader wordt daarin als een kwaadwillende entiteit gezien, waardoor andere aspecten van zijn 'zelf' uit het zicht verdwijnen (2019: 58). Blad keert zich evenwel tegen de opvatting dat herstelrecht verre zou moeten blijven van het strafrecht (het 'purisme'). De publieke terechtwijzing die gepaard gaat met mediation in strafzaken is immers een vorm van straf (2019: 61). Daarbij hangt uiteraard veel af van de manier waarop: vernederende afwijzingen moeten voorkomen worden. Bovendien, 'afwijzen betekent niet dat je per se de dader zwaar leed moet toevoegen'. De afkeuring kan beter gekoppeld worden 'aan gedragsbeïnvloedende verplichtingen, onder verwerping van de vergelding' (2019: 57).

John Blad heeft zijn gedachten steeds coherent en consistent verwoord. Mijns inziens staat zijn theorie als een huis. Ik zie drie kernpunten: ten eerste een subsidiaire benadering van straf: eerst komen de minst schadelijke vormen in aanmerking, dan pas de meer ingrijpende vormen. Ten tweede de opvatting dat de herstelsanctie een publieke afwijzing van het strafbare handelen impliceert. En ten derde de visie dat de herstelverplichting moreel van aard is: het bieden van morele genoegdoening aan het slachtoffer en de samenleving. Kenmerkend voor John Blads denken is een functionele en probleemgerichte rechtstheorie, aansluitend op de gedachten van zijn Rotterdamse leermeesters Louk Hulsman en Jack ter Heide. Vandaar zijn verzet tegen een 'te punitief, disfunctioneel discours' (2019: 58). Blads probleemgerichte rechtstheorie staat overigens ook open voor integratie van empirische onderzoeksbevindingen. Zijn opmerkingen over het 'verhaal van de dader' is daarvoor typerend. De bevindingen van de narratieve 
criminologie - een benadering die momenteel een opgang maakt - sluiten daarop naadloos aan.

Rondom veel inzichten die John Blad heeft verwoord, bestaat consensus in kringen van kritische juristen en criminologen. Dat geldt onder andere voor de notie van misdaadrecht of delictenrecht, welke passender is voor hetgeen rechters en officieren van justitie feitelijk doen - en waarvoor sommigen in de Moderne Richting zoals Gerard van Hamel al pleitten. Dat geldt ook voor de afwijzing van de intentionele leedtoevoeging. De leedstraf doorkruist het verantwoordelijkheidsbesef van de dader en moedigt weerspannigheid aan. Het publieke belang is daarmee bepaald niet gediend. Maar er zijn ook verschillen van inzicht die discussie zullen blijven losmaken. Heeft het strafbegrip geen legitimiteit zoals Lode Walgrave betoogt (2008) of zijn concepties van straf voorstelbaar die herstelgericht en constructief van aard zijn (Kool, 2020; Van Stokkom, 2016)? Is de uitgeoefende dwang bepalend voor het strafkarakter of juist de intentie van de straffer (Claessen, 2012)? Kan de morele confrontatie van de herstelgerichte afdoening als 'constructieve wraak' worden gezien (Kool, 2005 en 2020) of staat wraakuitoefening hoe dan ook in het teken van leed en verlies toebrengen? Dergelijke vragen zullen ongetwijfeld in de volgende jaargangen van dit tijdschrift opnieuw aan de orde worden gesteld.

\section{Literatuur}

Blad, J. (2000) Strafrecht en bemiddeling: opkomst en toekomst van herstelrecht in Nederland. Recht der Werkelijkheid, 21(2), 51-71.

Blad, J. (2001a) Het Tijdschrift voor herstelrecht: waarom, waartoe? Tijdschrift voor Herstelrecht, 1(1), 1-4.

Blad, J. (2001b) Van strafrecht naar herstelrecht? Tijdschrift voor Herstelrecht, 1(1), 41-53.

Blad, J. (2011) Het sanctieconcept van het herstelrecht. Sancties: tijdschrift over straffen en maatregelen, (4), 232-250.

Claessen, J. (2012) Pleidooi voor een ruimer strafbegrip of een strafrecht zonder straffixatie. Tijdschrift voor Herstelrecht, 12(4), 37-49.

Claessen, J. et al. (2017) Voorstel van Wet strekkende tot de invoering van een herstelgerichte afdoening via bemiddeling in strafzaken in het Wetboek van Strafvordering, inclusief Memorie van Toelichting. Oisterwijk: Wolf Legal Publishers.

Duff, A. (1992) Alternatives to Punishment - or Alternative Punishments? In: W. Cragg (ed.), Retributivism and its Critics. Stuttgart: Franz Steiner.

Kool, R. (2005) Herstel: een communicatieve vorm van wraak. Tijdschrift voor Herstelrecht, 5(3), 24-33.

Kool, R. (2020) Constructieve vergelding revisited. De grondslag van de straf vanuit herstelrechtelijk perspectief. Tijdschrift voor Herstelrecht, 20(4), ....

Kool, R. \& A. Wolthuis (2019) Vormingswerker, rechtstheoreticus en herstelrechtelijk pionier - Interview met John Blad. Tijdschrift voor Herstelrecht, 19(4), 50-63.

Stokkom, B. van (2016) Fatsoenlijk vergelden. Tijdschrift voor Filosofie, 78, 777-806.

Walgrave, L. (2008) Restorative Justice, Self-Interest and Responsible Citizenship. Devon: Willan Publishing. 